\title{
COLONIALISMO PORTUGUÊS, LUSOTROPICALISMO, RACISMO E LUTAS ANTIRRACISTAS - ENTREVISTA COM MARTA ARAÚJO
}

\author{
Otto Vinicius Agra Figueiredo (UEFS)* \\ https://orcid.org/0000-0002-0441-9875 \\ Jalusa Silva de Arruda (UNEB)** \\ https://orcid.org/0000-0002-1545-6823 \\ Marta Araújo (CES/UC)*** \\ https://orcid.org/0000-0002-2449-0011
}

\section{RESUMO}

Marta Araújo é doutora pela Universidade de Londres (IoE) e pesquisadora sênior do Centro de Estudos Sociais, Universidade de Coimbra (CES/UC). Nesta entrevista, abordou sua trajetória de investigadora dedicada aos temas relacionados ao racismo e sobre como a discussão adentrou as agendas de pesquisa em Portugal. Conhecedora do contexto brasileiro, Marta Araújo tratou da influência do pensamento de Gilberto Freyre e do lusotropicalismo nos intelectuais portugueses e no pensamento da elite política portuguesa sobre as consequências do colonialismo, assim como abordou o que, no Brasil, chamamos de ideologia da mestiçagem. Refletiu aspectos de caráter metodológicos sobre o desenvolvimento e a disseminação de pesquisas antirracistas e analisou criticamente a agenda de pesquisas sobre raça no contexto português, destacando a importância da articulação, da mobilização e da autonomia política do movimento negro no enfrentamento ao racismo.

Palavras-chave: raça; racismo institucional; colonialismo; lusotropicalismo; antirracismo.

\section{ABSTRACT}

\section{PORTUGUESE COLONIALISM, LUSOTROPICALISM, RACISM AND} ANTI-RACIST STRUGGLES - INTERVIEW WITH MARTA ARAÚJO

Marta Araújo holds a Ph.D. from the University of London (IoE) and is a senior researcher at the Center for Social Studies, University of Coimbra (CES/UC). In this interview, she addressed her trajectory as a researcher dedicated to themes related to racism and how the theme entered the research agendas in Portugal.

Doutor pela Universidade do Estado da Bahia (UNEB) e professor assistente da Universidade Estadual de Feira de Santana (UEFS), Feira de Santana, Bahia, Brasill. E-mail: ottoagra@gmail.com

** Doutora pela Universidade Federal da Bahia (UFBA) e professora auxiliar da UNEB, Campus XV, Valença, Bahia, Brasil. Pesquisadora associada do Núcleo de Estudos Interdisciplinares sobre a Mulher (NEIM/UFBA), Salvador/BA. E-mail: jsarruda@uneb.br

*** Doutora pela Universidade de Londres (IoE) e pesquisadora sênior do Centro de Estudos Sociais, Universidade de Coimbra. (CES/UC). Coimbra, Portugal. E-mail: marta@ces.uc.pt 
With knowledge of the Brazilian context, Marta Araújo approached the influence of Gilberto Freyre's thought and lusotropicalism on Portuguese intellectuals and on the Portuguese political elite's understanding of the consequences of colonialism, and also addressed what in Brazil we call miscegenation ideology. She reflected on methodological aspects of the development and dissemination of anti-racist research and critically analyzed the research agenda on race in the Portuguese context, highlighting the importance of articulation, mobilization, and political autonomy of the black movement in the fight against racism.

Keywords: race; institutional racism; colonialism; lusotropicalism; anti-racism.

\section{RESUMEN}

\section{COLONIALISMO PORTUGUÉS, LUSOTROPICALISMO, RACISMO Y LUCHA ANTIRACISTA - ENTREVISTA CON MARTA ARAÚJO}

Marta Araújo tiene un doctorado de la Universidad de Londres (IoE) y es investigadora senior en el Centro de Estudios Sociales de la Universidad de Coimbra (CES/UC). En esta entrevista, abordó su trayectoria como investigadora dedicada a temas relacionados con el racismo y cómo la discusión entró en las agendas de investigación en Portugal. Conociendo el contexto brasileño, Marta Araújo abordó la influencia del pensamiento de Gilberto Freyre y el lusotropicalismo en los intelectuales portugueses y en el pensamiento de la élite política portuguesa sobre las consecuencias del colonialismo, además de abordar lo que en Brasil llamamos ideología del mestizaje. Reflejó aspectos metodológicos del desarrollo y difusión de la investigación antirracista y analizó críticamente la agenda de investigación sobre raza en el contexto portugués, destacando la importancia de la articulación, movilización y autonomía política del movimiento negro en la lucha contra el racismo.

Palabras clave: raza; racismo institucional; colonialismo; lusotropicalism; antirracismo.

\section{Introdução $0^{1}$}

Marta Araújo é licenciada em Ciências da Educação pela Universidade de Coimbra (UC), mestra em Educação Intercultural: raça, etnia e cultura e doutorada na área de Sociologia da Educação e Raça pela Universidade de Londres (Instituto da Educação). Em 2003, ingressou no Centro de Estudos Sociais (CES/UC) para o pós-doutorado e, desde 2005, é investigadora contratada para o desenvolvimento de pesquisas junto ao Núcleo de Estudos sobre Democracia, Cidadania e Direito (DECIDe). Ainda no CES, é docente nos programas de doutorado Democracia no Século XXI (CES e

1 Texto revisado por Letícia Maria de Souza Pereira.
Faculdade de Economia/UC) e Human Rights in Contemporary Societies (CES/UC) e colaboradora do Observatório da Religião no Espaço Público (POLICREDOS). Entre 2018 e 2020 foi pesquisadora visitante na Universidade de Helsinque, Finlândia e professora convidada da Black Europe Summer School no International Institute for Research and Education, em Amsterdã, Holanda.

É uma das autoras da obra Os contornos do eurocentrismo: raça, história e textos políticos (ARAÚJO; MAESO, 2016) e organizadora do livro Eurocentrism, racism and knowledge: debates on history and power in Europe and the Americas (ARAÚJO; MAESO, 2015), além de 
possuir diversos capítulos de livros e artigos científicos publicados. Os interesses atuais de pesquisa de Marta Araújo estão relacionados às políticas públicas, especialmente sobre antirracismo, integração e educação, desigualdades raciais e lutas antirracistas; eurocentrismo, produção de conhecimento, disseminação da história e o ensino de questões relativas ao colonialismo, escravidão e racismo; e antirracismo em perspectiva histórica e comparada. É integrante da Associação Internacional de Ciências Sociais e Humanas em Língua Portuguesa, da International Sociology Association (ISA) no Research Committee on Racism, Nationalism and Ethnic Relations e da Sociedade Portuguesa de Ciências da Educação.

$\mathrm{Na}$ entrevista realizada no dia 23 de julho de 2019, na sede do CES em Coimbra, Marta Araújo abordou sua trajetória de investigadora dedicada aos temas relacionados ao racismo que, em certa medida, revela como a questão adentrou as agendas de pesquisa em Portugal. Conhecedora do contexto brasileiro, Marta Araújo tratou da influência do pensamento de Gilberto Freyre e do lusotropicalismo na compreensão de intelectuais portugueses e da elite política portuguesa sobre as consequências do colonialismo e do que conhecemos no Brasil como ideologia da mestiçagem. Refletiu aspectos de caráter metodológico sobre o desenvolvimento e disseminação de resultados de pesquisas antirracistas e analisou criticamente a agenda de pesquisas sobre raça no contexto português, destacando a importância da articulação, da mobilização e da autonomia política do movimento negro português no enfrentamento do racismo.

\section{Gostaríamos que nos contasse como foi} seu encontro com os temas colonialismo, racismo e xenofobia e como esses temas se engendraram na sua trajetória profissional e acadêmica.

ARAÚJ0: Na verdade, essas temáticas eram praticamente ausentes nas universidades portuguesas quando iniciei os meus estudos a nível superior. No âmbito da licenciatura em Ciências da Educação, tinha uma disciplina - que foi a que mais me interessou - e que abordava como o sistema educativo reproduzia e era também produtor de desigualdades sociais, sobretudo a partir do trabalho de Pierre Bourdieu. Essa disciplina marcou o meu olhar sobre a educação, pois o meu interesse pela área incidia sobre os processos políticos que lhe estão associados, e não tanto as questões ligadas à pedagogia e didática. Estávamos em 1992-1993 e em 1991 tinha sido criado aquele que foi o primeiro organismo em Portugal ligado à questão da diversidade na educação, na ocasião nomeado Secretariado Coordenador de Programas de Educação Multicultural (SCOPREM). Naquele momento, o professor desta disciplina, o Joaquim Pires Valentim, que tinha um olhar crítico sobre a forma como se abordavam as questões da diversidade na educação em Portugal, proporcionou que eu participasse de uma ação em Barcelona organizada por ativistas europeus que trabalhavam com a questão da imigração e do racismo. Foi meu primeiro contato com o contexto onde essas questões de fato eram debatidas, não só acadêmica, mas também politicamente. Em 1993, frequentei o programa Erasmus no Sul da França, na Universidade de Aix-Marseille II. Nesse contexto, testemunhei inúmeras situações cotidianas de racismo, num momento em que se vivia na Europa forte ascensão da extrema direita e de Jean Marie Le Pen (pai) e ocorreram uma série de assassinatos de cunho racial. Em Portugal, debates sobre violência racista se tornaram mais visíveis entre $1994 \mathrm{e}$ 1995, particularmente após a morte do Alcindo Monteiro em Lisboa ${ }^{2}$. Assim, destaco estas duas experiências: o contato com o mundo do

2 Refere-se a Jean-Marie Le Pen, político francês pertencente à Frente Nacional, partido nacionalista da extrema direita francesa. É pai de Marine Le Pen, deputada do Parlamento Europeu desde 2004, também integrante da Frente Nacional. Na noite de 10 de junho de 1995, Alcindo Monteiro, homem jovem português de origem cabo-verdiana, foi agredido até a morte por um grupo de skinheads no Bairro Alto, em Lisboa. 
ativismo e a minha própria trajetória acadêmica. Quando regressei a Portugal, fiz estágio de investigação sobre racismo e desigualdades na educação em Leiria [cidade portuguesa localizada na região denominada Centro, atualmente com pouco mais de 125.000 habitantes], em um bairro que era habitado por considerável percentual de pessoas negras, vindas especialmente de Angola e Cabo Verde. Dediquei o estágio a estudar as desigualdades sociais e educativas que marcavam as trajetórias das crianças que habitavam nesse bairro. A partir daí, o meu percurso acadêmico foi orientado para o estudo das desigualdades étnico-raciais. Em 1995, em uma viagem a Londres, tive contato com o trabalho daquele que veio a ser meu supervisor, o professor David Gillborn, então na Universidade de Londres, que acabava de publicar um livro sobre racismo, antirracismo e educação (GILLBORN, 1995) num momento em que quase não se podia dizer a palavra racismo em muitos contextos universitários europeus. Foi então que, em 1996, fui para Londres fazer o mestrado e, mais tarde, o doutorado, que concluí em 2003. Esse período representou para mim uma oportunidade excepcional no sentido em que tinha acesso a disciplinas, literatura e debates que não existiam em Portugal naquele período. Obviamente, uma coisa eram as leituras que fazíamos; mas, quando começávamos a entrar no campo, a situação não estava assim tão avançada como eu imaginava e a perpetuação do racismo dava-se na mesma, ali à nossa frente. Porém, de fato, o contexto britânico proporcionou oportunidade única para aprofundar o tema em termos de debate teórico e também político, já que iniciei os estudos doutorais no ano seguinte à eleição de Tony Blair em 1997 e o seu New Labour (o Novo Partido Trabalhista), após 18 anos de governos conservadores (Tories), iniciados com a eleição de Margaret Thatcher em 1979. Na minha tese de doutorado, investiguei o impacto racializado das políticas públicas e examinei como as iniciativas do Novo Partido Trabalhista nos anos finais da década de 1990 continuaram a per- petuar as desigualdades raciais na educação, apesar da ênfase de discursos e políticas para a inclusão social que o demarcavam do anterior regime (ARAÚJO, 2007; 2009). Após investigar sobre o contexto britânico, interessava-me debater o tema em Portugal, considerando que ainda eram questões muito incipientes. No meu regresso, em 2003, decidi fazer o pós-doutorado em continuidade com o que havia estudado no doutorado. A minha investigação de então procurava perceber como é que o racismo se manifestava no cotidiano das escolas e na trajetória de crianças negras. Estudei uma escola privada e uma escola pública, em um caso com estudantes negros com estatuto social muito privilegiado e no outro, pelo contrário, com crianças institucionalizadas e bastante excluídas. Mais tarde, a partir desta experiência, foquei no ensino da história de África em Portugal e na análise do eurocentrismo nos livros didáticos portugueses.

Na época da licenciatura, quer dizer, no início dos anos de 1990, havia outros estudos ou atividades que abordassem as desigualdades das relações raciais na educação?

ARAÚJ0: Nas Ciências da Educação, em Coimbra, abordávamos de forma mais ou menos elementar os processos de distinção social e acadêmica através da escola, sobretudo a partir de formações de classe e relações de gênero e, mais tarde, a questão da desigualdade étnico-racial. 0 tema ainda era muito novo em Portugal, mas o meu orientador de estágio, Joaquim Pires Valentim, estava preparando um livro, publicado em 1997, que deu importante contribuição ao debate (VALENTIM, 1997). Antes disso, em 1995, houve um primeiro grande encontro, quer dizer, uma grande conferência promovida pela Fundação Calouste Gulbenkian sobre diversidade cultural ${ }^{3}$. Foi um evento

3 A Fundação Calouste Gulbenkian é uma instituição filantrópica portuguesa com sede em Lisboa com fins caritativos, artísticos, educativos e científicos. A Fundação desenvolve suas atividades através de apoios concedidos desde Portu- 
muito pouco crítico, no qual os professores apresentaram as atividades que desenvolviam para visibilizar o Outro - o típico "festival multicultural" - numa lógica de "constatação da diferença" e de promoção da diversidade, mas algo que, no fundo, meramente promovia a reificação da diferença e não se propunha repensar a história e a identidade nacionais. Portanto, quando fui para o Reino Unido, foi num contexto onde era muito difícil encontrar enquadramento institucional para desenvolver os meus estudos em Portugal, algo que se alterou significativamente nos últimos anos.

\section{No livro Os contornos do eurocentrismo:} raça, história e textos políticos (ARAÚJ0; MAES0, 2016) há a afirmação de que os livros didáticos de História analisados na pesquisa, que resultaram na obra, exaltam a conquista dos colonizadores portugueses e a crueldade da colonização espanhola nas Américas, mas sem referência à resistência indígena, construindo as figuras do "bom" e do "mau" colonizador como se o português tivesse sido um "bom colono" e "não racista". Seria influência do lusotropicalismo?

ARAÚJ0: Sim, sem dúvida. No projeto Raça e África em Portugal: um estudo sobre manuais escolares de história (2008-2012), o que vimos em vários dos livros didáticos de História analisados (para alunos dos 12 aos 15 anos de idade) é essa ideia que o colonialismo português não foi "tão mau" como os demais ${ }^{4}$. Essa ideia surgia de forma mais ou menos explícita, o que varia conforme os autores. Frequentemente,

gal nos Países Africanos de Língua Portuguesa (PALOP) e Timor-Leste, bem como nos países com Comunidades Armênias. Disponível em: https://gulbenkian.pt/fundacao/ apresentacao/. Acesso em: 15 mar. 2020.

40 projeto de investigação Raça e África em Portugal: um estudo sobre manuais escolares de história foi desenvolvido entre 2008-2012 e financiado pela Fundação para a Ciência e para a Tecnologia (FCT). Para mais informações, ver: https://www.ces.uc.pt/projectos/rap. nas narrativas sobre a chamada "expansão portuguesa", encontramos as fórmulas narrativas mais comuns do lusotropicalismo e que levam à despolitização do colonialismo, designadamente as que invisibilizam a violência colonial e os processos de resistência, quer da população indígena, quer da população escravizada e que auxiliam a banalização dos processos coloniais europeus. Neste sentido, é uma derivação do campo discursivo do lusotropicalismo que tem implícita uma construção de certas potências colonizadoras como sendo mais violentas, agressivas, ou hostis - que seria o caso espanhol ou britânico -, por contraponto ao colonialismo português, tido como mais benevolente. Cabe notar que é quando se abordam essas questões que geralmente se trata o racismo em relação aos processos coloniais como o britânico ou o francês, mas não em relação ao português. Portanto, nos livros didáticos, não se costuma falar do projeto colonial português como um projeto racista, por exemplo. Nos livros analisados, geralmente não se faz qualquer alusão ao Estatuto do Indigenato e aos diferentes direitos que lhe estavam associados, concebidos por linhas que são raciais ${ }^{5}$. Agora, por outro lado, há que ter em conta que o lusotropicalismo tem por base a ideia de excepcionalismo nacional, neste caso, dos portugueses. Esses excepcionalismos nacionais foram sendo construídos ao longo do século XIX e ajudaram a sustentar a ideia que existe o "colonialismo português", o "colonia-

5 O Estatuto do Indigenato foi o agrupamento de um conjunto de disposições legais que impunha existência de direitos políticos e sociais diferenciados nas então colônias portuguesas da Guiné, de Angola e de Moçambique. 0 Estatuto do Indigenato foi regulado pela Lei no $\mathbf{2 7 7}$, de 15 de agosto de 1914 e depois pelo Estatuto Político, Social e Criminal dos Indígenas de Angola e Moçambique, de 1926. Ressalta-se que, no contexto colonial, a noção de indígena foi tomada como sinônimo de negro e de africano (MENESES, 2010). 0 Estatuto do Indigenato "representou, no contexto do pensamento político republicano, um sistema que assentava numa doutrina jurídica que postula a ideia de que os africanos eram cultural, linguística, moral e intelectualmente incapazes de exercer a cidadania portuguesa, apostando no reforçar da dissociação entre nacionalidade (como pertença étnica, e portanto detentor de direitos privados) e cidadania" (MENESES, 2010, p. 87). 0 Estatuto do Indigenato foi abolido pelo Decreto-Lei no 43.893, de 6 de setembro de 1961. 
lismo britânico" e que existe hoje em dia um "racismo à brasileira", o "racismo à portuguesa", como se fossem processos verdadeiramente distintos e estanques. Lido assim, o lusotropicalismo é a ideologia que, no contexto português, veio fazer o apanágio da tolerância do colonizador português, mas não é caso único. Outros povos tiveram igualmente os seus próprios mitos de tolerância: por exemplo, o mito da democracia racial no Brasil e a ideologia da color-blindness nos Estados Unidos da América (EUA), da justiça e equidade na Inglaterra ou da tolerância na Holanda. Quando se hierarquizam os projetos coloniais europeus em relação a violência ou ao racismo, acabamos por desembocar numa mera averiguação da culpa - quem foi, moralmente, o colonizador mais e menos condenável? - ao invés de realizar análise da forma como o colonialismo e a escravidão foram incorporadas nas narrativas nacionais de forma a lhes conceder legitimidade. Podemos, assim, compreender que o lusotropicalismo não "inventou" o mito da excepcionalidade dos portugueses, mas se ancorou em processos de formação nacional de finais do século XIX no contexto de rivalidades coloniais na Europa. Ocorreu o mesmo com outras ideologias nacionais que serviram para legitimar processos coloniais de opressão e exploração racial. Um outro aspecto que me parece ser importante referir é a necessidade de ir além da interpretação do lusotropicalismo como mito errado ou como mera conclusão explicativa e situá-lo em um contexto político sujeito a permanente contestação. Em Portugal, a partir de meados do século passado, o lusotropicalismo surgiu em um cenário em que se procurava justificar e legitimar o projeto colonial face às crescentes pressões internacionais, sobretudo das Nações Unidas, sustentando a ideia que não era necessário conceder as independências ou descolonizar porque Portugal não tinha "colônias", mas sim "províncias ultramarinas" com as quais mantinha "relações de natureza convivial". Essa ideologia e os arranjos legais e institucionais nos quais se apoiavam eram ativamente contestados, designadamente pelos movimentos de libertação nacional africanos que progressivamente forçaram o fim do Estado Novo e do projeto colonial português.

\section{Quer dizer que pretende-se passar a impressão de relações harmônicas?}

ARAÚJ0: Sim, pois deste modo passa-se no discurso oficial a noção que Portugal não tinha colônias e que era antes um país multirracial, multicontinental, multirreligioso. Então, é importante falar da herança do lusotropicalismo, mas é importante não estarmos sempre a excepcionalizar o contexto português ou o contexto brasileiro. Nos debates internacionais, deparamo-nos com inúmeras outras ideologias que foram sendo desenvolvidas para justificar a legitimidade de processos coloniais e imperiais, que vinham trazer a civilização, que eram baseados na tolerância etc. Quero dizer com isso que o lusotropicalismo é uma expressão no contexto de língua portuguesa que assumiu essa legitimação do mundo colonial, mas que não representa a invenção dos mitos de tolerância colonial.

Gostaríamos de comentar a importância da figura do Gilberto Freyre para Portugal, especialmente em relação à visita que fez aqui na década de 1950 a convite do ditador António de Oliveira Salazar. Gilberto Freyre (1952) esteve em Lisboa, em Coimbra, visitou universidades e esteve nas colônias portuguesas em África, resultando no livro Aventura e rotina. Parece que houve acolhimento das ideias de Gilberto Freyre (1998), com certa importação do olhar de quem havia escrito Casa Grande \& Senzala. Gostaríamos que falasse um pouco sobre isso.

ARAÚJ0: Muitas vezes, os pesquisadores brasileiros que nos visitam [em referência ao 
CES] têm como pressuposto de que temos um entendimento comum sobre o que é o lusotropicalismo, mas o lusotropicalismo teve, em Portugal, contornos diferentes e penso que o trabalho de Cláudia Castelo (1998), com o título $O$ modo português de estar no mundo: 0 luso-tropicalismo e a ideologia colonial portuguesa (1933-1961), é um trabalho essencial. Outro trabalho relevante, neste assunto para o contexto português, é o de Miguel Vale de Almeida (2000), Um mar da cor da terra: raça, cultura e política da identidade. São dois livros que marcavam de fato uma viragem, a partir de uma análise crítica do que foi o lusotropicalismo. 0 trabalho de Cláudia Castelo nos permitiu distinguir o que foi o pensamento do Gilberto Freyre e os seus usos no contexto brasileiro face a como ele foi apropriado no contexto português. De forma resumida, o que ela nos diz é que na década de 1930, quando o Freyre publicou o Casa Grande \& Senzala, a questão da miscigenação biológica causava grande ansiedade às elites portuguesas, pois a possibilidade de miscigenação biológica era lida como uma abertura à degeneração racial. Assim, como a Cláudia Castelo analisa, as teses de Freyre não eram muito bem-vindas nesses meios, especialmente a partir dos círculos intelectuais (políticos e acadêmicos). Foi apenas nos anos de 1950, quando começou a crescer a pressão internacional das Nações Unidas para que Portugal concedesse as independências às antigas colônias (Cabo Verde, Guiné-Bissau, Angola, Moçambique e São Tomé Príncipe), que Gilberto Freyre foi convidado a vir a Portugal e as suas teses foram apropriadas de forma parcial, sendo o lusotropicalismo interpretado como a abertura dos portugueses à miscigenação cultural, mas não biológica. Portanto, salvaguardava-se a ideia de uma pureza racial, de um pressuposto de que os portugueses são 'brancos' e são vistos como tal, o que contrastaria com o caso brasileiro. Por exemplo, em um dos livros didáticos que analisamos no projeto Raça e África em Portugal: um estudo sobre os manuais escolares de história que citei ante- riormente, encontramos uma imagem em que se pretendia mostrar a miscigenação que teria ocorrido no Brasil em consequência do projeto colonial. A imagem consistia na composição de três fotografias distintas, no caso uma figura com traços indígenas, figuras baianas com traços africanos e figura com traços de europeus (todas com os seus trajes característicos), para ilustrar a miscigenação. Na verdade, a imagem apenas reproduz a existência de tipos raciais - quer dizer, o indígena, o negro, o branco que não convivem e nem se misturam sendo apresentados como arquétipos raciais. Essa imagem denota que a interpretação dos autores dos livros é que a miscigenação consistiu na coexistência de populações diversas, mas que não necessariamente estão interligadas.

\section{Quer dizer, a mestiçagem deveria ser evidenciada.}

ARAÚJ0: A verdade é que ainda continuamos a falar na mestiçagem, mas no lado português falamos no aspecto cultural e ainda que até possamos admitir que houve o sexual, temos alguma dificuldade em discutir esse legado histórico em Portugal. Exemplarmente, a população escravizada que vivia no território entre os séculos XV e XVIII chegou a constituir cerca de $10 \%$ da população de Lisboa, mas depois deixamos de ter registro dessa população. Até há pouco parecia haver certa ansiedade em discutir estes temas, sobretudo considerando as suas implicações. Por que não suscitam mais curiosidade e investigação? Isso para dizer que é importante produzir novas leituras sobre o contexto português para compreender como é que Gilberto Freyre foi apropriado pelas elites em Portugal.

Isso é muito interessante porque em Casa Grande \& Senzala, Gilberto Freyre fala dos portugueses como pré-dispostos à miscigenação e faz referência à ocupação árabe, por exemplo. Para ele, digamos assim, é como se os 
portugueses já tivessem um ethos para miscigenação.

ARAÚJO: Claro, foi assim que fundamentou a sua tese. Segundo Freyre, a suposta aptidão do povo português para a miscigenação biológica e interpenetração cultural com o povo dos trópicos resultava da natureza miscigenada dos próprios portugueses, que emergiram de longo contato com os mouros e os judeus na Península Ibérica. Agora, a leitura sobre a natureza desse contato histórico é aberta à disputa: alguns subscritores do lusotropicalismo vão defender essa ideia, da mesma forma como outras correntes que vão dizer que o islã na Península Ibérica é exemplo de abertura por terem sido mais tolerantes com as pessoas de fé cristã, ao passo que certos Reinos Cristãos obrigavam à conversão na Península Ibérica. Essas são questões sobre as quais se continua a levantar debate e que estão em aberto. Portanto, há uma série de contradições na maneira como essa ideologia vai ser mobilizada: ainda que se aprenda desde a escola que somos o resultado da mistura de muitos povos, isso não quer dizer que as pessoas não se autoidentifiquem hoje como brancas. Independentemente de, em contextos acadêmicos europeus, os portugueses não serem sempre vistos como brancos, o que nos relembra como as categorias raciais são por natureza ambíguas, relacionais e estão em constante construção.

\section{Muitas vezes a visão que se tem é que a} Europa é homogeneamente branca, como se não existissem diferenças.

ARAÚJO: Penso que aqui a questão que se coloca não é tanto de reconhecer a diversidade existente entre as populações européias, mas de questionar as fronteiras históricas e os processos de inclusão e exclusão em relação a noções do que é a Europa e do que é ser europeu. Temos de nos questionar como as sociedades européias foram (ou não) sendo construídas historicamente como brancas e reconhecer que tais construções ultrapassam em muito critérios fenotípicos como a cor de pele. No século XIX, os irlandeses, por exemplo, não eram considerados brancos. Há ideologias que vão construindo certos povos como mais ou menos "puros" do ponto de vista racial e que mudam ao longo do tempo. Da mesma forma, a maneira como entendemos as categorias raciais também sofreu mudanças: ser negro hoje é diferente do que era ser negro no contexto britânico dos anos de 1970, em que a categoria black era usada para agregar tanto pessoas que nós hoje reconheceríamos como negras, de ascendência africana ou caribenha, como era usada até ao Rushdie Affair de 1989 para designar as populações do subcontinente asiático, especialmente da Índia, Bangladesh e Paquistão. 0 termo black era usado no sentido de não-branco, como termo agregador de todos aqueles que eram afetados pelo racismo, o que ilustra que é necessário discutir e problematizar os conceitos e lembrar que as categorias de debate mudam em diferentes tempos e lugares. Voltando ao debate sobre o lusotropicalismo, eu diria que essas formulações continuaram a informar os debates em termos de discurso oficial repetidamente, especialmente sobre as decisões políticas em matérias ligadas à interculturalidade e a diversidade, que se refugiam neste tipo de abordagem para justificar a ausência de medidas estruturais e de formas de monitoramento e combate ao racismo. Logo, o lusotropicalismo, como dispositivo discursivo que sustenta a negação do racismo, é ainda muito evidente. Se não nos reconhecemos como racistas, para que precisamos de ter um arcabouço institucional e legislativo, de ter iniciativas e medidas políticas para lidar com o racismo? Isso já era visível nos idos anos de 1990. O preâmbulo ao despacho da criação deste organismo que eu mencionei, o Secretariado Coordenador de Programas de Educação Multicultural, é uma declaração lusotropicalista que enfatiza a cultura "aberta e mestiça", "universalista" e "ecumênica" do povo português e a constrói como pioneira do contato com outros povos que colonizou (POR- 
TUGAL, 1991). A noção do português como benevolente é o ponto de partida para lidar com o que foi construído como o Outro. 0 português está ali intocável, historicamente consagrado como "aberto", "tolerante" e "ecumênico" e, portanto, o que temos de fazer é tomar medidas para que o Outro possa se integrar na "nossa" sociedade, mas sem que nunca problematizemos os porquês da nossa própria sociedade causar obstáculos para essa integração. Se pensarmos nas medidas e iniciativas públicas relacionadas à integração nos últimos 10 ou 15 anos, isso é evidente. Igualmente em termos de discursos políticos: por exemplo, o organismo público que entre 2007 e 2014 se designou Alto Comissariado para a Imigração e o Diálogo Intercultural, promoveu uma coleção chamada Portugal Intercultural que, no fundo, é a materialização da abordagem lusotropicalista. Essa coleção foi usada para mostrar seletivamente o pioneirismo português em matéria de contato cultural. Ilustrou-se, dentre outras, como foi o contato cultural dos portugueses na Ásia e selecionaram-se casos como o Japão (o país do continente asiático mais embranquecido na história) para mostrar como os portugueses procuraram estabelecer relações de intercâmbio e troca. Processos históricos como a escravização, ainda que não totalmente apagados da narrativa, são relatados de passagem como simplesmente a "mãe" de muitas sociedades americanas atuais. Nesse sentido, o legado da escravização é reduzido à existência de diversidade em sociedades contemporâneas como o Brasil, de maneira despolitizada. Quando se evade o projeto colonial português em África e no Brasil e se foca na Ásia e neste "contato cultural", quase parece que podemos falar desse tal "modo do português estar no mundo", consentâneo com as teses de Gilberto Freyre e do lusotropicalismo. Essa visão cria a noção de que o português teve relações harmoniosas com muitos povos diferentes e só os negros é que "colocam demandas", só os negros é que estão "a chamar a atenção da escravidão", só eles estão a querer "falar de cotas" e "de história e reparações". Assim, essas maneiras de falar de interculturalidade e contato cultural, têm implícitas certas interpretações da História na qual se pode perceber hierarquização racial dos povos, inclusive na sua relação com os portugueses. Se, para além da proeminência em termos do discurso, nós pensarmos em eventos, projetos, ou iniciativas de propostas públicas recentes - como a recusa em repensar o nome do Padrão dos Descobrimentos, ou a recente proposta, em 2018, para a criação de um Museu das Descobertas em Lisboa (apesar da polêmica que gerou) - vemos que os debates do presente continuam de certa forma atravessados pelo lusotropicalismo ${ }^{6}$. A ideia de certa hospitalidade e convivialidade fácil e harmoniosa é uma visão que se mantém até hoje em termos de discurso político. Claro que hoje em dia temos uma crescente visibilidade do movimento associativo, quer da população negra ou cigana, e essas narrativas têm tido muito mais contestação pública, ou pelo menos se apresentado de forma mais visível. Em termos acadêmicos, a influência do lusotropicalismo também se fez sentir e não foi por casualidade que eu mencionei os trabalhos da Cláudia Castelo (1998) e de Miguel Vale de Almeida (2000), porque de fato vieram romper com as abordagens dominantes sobre este tema em Portugal. A própria marginalidade da agenda sobre o racismo na investigação reflete isso. A agenda de pesquisas que visa romper com a abordagem eurocêntrica e positivista do racismo - que procura "medir" o preconceito das pessoas numa escala - e adentra nos processos históricos de formação nacional e coloniais nos quais raça e racismo emergiram, tem sido marginalizada, inclusive em termos de financiamento. É preciso que isso seja dito.

6 O debate em torno da criação do Museu das Descobertas em Lisboa, em 2018, resultou de proposta eleitoral de Fernando Medina, Presidente da Câmara Municipal de Lisboa, que não se materializou. Há diversas matérias jornalísticas a respeito, uma das quais: https://expresso. pt/cultura/2018-04-12-A-controversia-sobre-um-Museuque-ainda-nao-existe.-Descobertas-ou-Expansao-\#gs. VCXOdCg. Acesso em: 14 mai. 2020. 
Então, há falta de interesse na investigação científica por determinadas temáticas, sobretudo, quando se aborda as questões das diferenças e do racismo especificamente no contexto português? Podemos dizer que há um misto de negação de algumas questões com despolitização do que foi necessariamente o colonialismo, que marca o convívio com as diferenças pela celebração da diversidade? Essas dimensões em algum momento se encontram nos âmbitos político e acadêmico?

ARAÚJO: Sim. A marginalidade da agenda de investigação sobre racismo seguiu, sobremaneira, até à década de 1990. A partir daí começou haver maior interesse, ainda residual e, como disse, incidindo sobre o estudo do preconceito, muito no âmbito da psicologia social. Destacam-se aqui os trabalhos coordenados por Jorge Vala (e outros) desde a segunda metade dos anos de 1990, denominado Atitudes sociais dos portugueses, cujos primeiros resultados foram publicados no ano 2000 e, especialmente, o Expressões dos racismos em Portugal, cuja primeira edição foi publicada em 1999 (VALA; BRITO; LOPES, 2015)7. Foram trabalhos muito importantes para questionar a negação do racismo na sociedade portuguesa. Porém, nem sempre os trabalhos sobre racismo na psicologia social dialogaram com o contexto histórico e sociopolítico no qual se formaram tais preconceitos e atitudes, designadamente a história colonial portuguesa. Por outro lado, assistimos também, a partir do contexto acadêmico português, a maior visibilidade dos trabalhos sobre a memória colonial, como a chamada "guerra colonial", mas mais frequentemente abordada do ponto de vista dos solda-

7 A entrevistada refere-se ao programa Atitudes Sociais dos Portugueses (ASP) que promove pesquisas e publicações, editada pela Imprensa de Ciências Sociais (ICS). Para mais informações: http://asp.ics.ul.pt/?page_id=45. Acesso em: 14 mai. 2020. dos brancos que lutaram nas diferentes frentes de guerra e só mais recentemente sob o ponto de vista dos próprios movimentos de libertação africanos. Obviamente, noutros contextos, há maior multiplicidade de agendas de investigação. 0 que pretendo enfatizar é que no caso português ainda se debate muito sobre a chamada "guerra colonial" sem considerar que se deve incluir como estruturante a contribuição dos movimentos de libertação nacional africanos e da sua agenda política para a Revolução do 25 de abril de 1974 e a construção do Portugal democrático, por exemplo. E se nos últimos 10 ou 15 anos é mais perceptível a influência dos estudos pós-coloniais em Portugal, mesmo assim, até há pouco tempo eram relativamente marginalizadas abordagens que considerassem o contexto histórico-político de raça e racismo. Sem dúvida, estão aqui em operação processos de seletividade na agenda científica e política.

No Brasil, apesar da existência da Lei n 10.639/2003, pesquisas dão conta que ainda há grandes desafios para implementá-la, tais como a formação de professores (inicial e continuada) de forma inadequada, os currículos eurocêntricos, a gestão escolar centralizadora e outras questões. Como você observa a relevância e os limites para esse tipo de ensino?

ARAÚJO: De fato, o caso brasileiro é absolutamente relevante para os debates sobre as intersecções entre raça, história e educação, dado que em poucos contextos temos visto tantos avanços como os que foram conseguidos no Brasil. Obviamente, o avanço não foi só a legislação na qual culminou, mas toda a agenda de luta do movimento negro durante o século XX, como citam os trabalhos de Amílcar Pereira (2016) e Nilma Gomes (2017) ${ }^{8}$. Todavia, de fato, a lei é o culminar de longo processo. o Brasil é um caso de estudo absolutamente

8 Ver também Verena Alberti e Amílcar Pereira (2007). 
relevante, precisamente porque na Europa está praticamente tudo por fazer nesta matéria. Recentemente, o relatório periódico europeu, publicado em setembro de 2018 pela Comissão Européia contra o Racismo e a Intolerância (ECRI), fez crítica ao ensino da história colonial em Portugal e sugeriu que o país deveria repensar o ensino do colonialismo e da escravização (ECRI, 2018). Diversas matérias veiculadas nos meios de comunicação abordaram a questão, inclusive fazendo menção ao projeto que coordenei e que mencionei antes sobre os livros didáticos escolares (ARAÚJO; MAESO, 2016). Em vários casos, a problemática era abordada a partir de uma construção da questão como um não-problema, ou seja, como se a crítica às diretrizes curriculares, aos livros didáticos e às práticas pedagógicas estivessem fora de lugar. Aliás, vozes das elites portuguesas, tanto historiadores acadêmicos como profissionais ligados ao ensino da História, argumentaram que os relatores da ECRI não conheciam os livros didáticos portugueses, que estavam a criticar por criticar, que nem sequer conheciam a realidade portuguesa, porque não havia problema nenhum com a maneira como era ensinada a história do colonialismo português. Apesar de estudos como o nosso terem tido mais atenção nos últimos tempos, só recentemente os maiores partidos políticos começaram a colocar o assunto como uma questão [a entrevistada lembra que, em 13 de maio de 2019, foi convidada a abordar o assunto em audiência na Assembleia da República conduzida pela Comissão de Assuntos Constitucionais, Direitos, Liberdades e Garantias]. Quero com isso salientar que, em diferentes contextos europeus, ainda nem sequer conseguimos conceber que há um problema que requer resposta que é de todo sistema educativo e de conhecimento. Se, em Portugal, continuamos a negar que há um problema com o ensino do colonialismo português, no contexto britânico há bastante tempo existe o chamado Black History Month, o Mês da História Negra. Vocês no Brasil conseguiram dar o passo seguinte: não basta uma semana, não precisamos só do Dia da Consciência Negra, não precisamos de um mês, o que nós precisamos é de mudança estruturante dos cânones do conhecimento, não apenas nas escolas, mas também nas universidades, exatamente para fazer os enfrentamentos que são necessários. Ora, na Europa, para você dar tal passo, é preciso reconhecer que a população negra é integrante da Europa. A população negra é portuguesa, é britânica, é francesa e deve fazer parte do nosso imaginário de pertença nacional. E, como tal, essa História que se tem de se repensar é uma História que é de todos os portugueses, de todos os britânicos, de todos os franceses e daí por diante. 0 que vocês conseguiram no Brasil tem a ver com a forma como certas lutas se organizaram para redefinir o que é a nação brasileira, porque é muito fácil para nós europeus dizermos que a população no Brasil é diferente e "multirracial". Contudo, esta maior democratização do espaço público do ponto de vista racial, não se conseguiu pela simples existência de pessoas com "tom de pele diferente" como se costuma dizer, nem meramente por um decreto. Conseguiu-se como o resultado de lutas políticas concretas que têm conseguido levar a um maior reconhecimento do papel do negro na sociedade brasileira, ainda que constantemente sujeita a reveses. Não foi conseguida gratuitamente e nem concedida de forma benevolente, mas foi um processo de luta. Eu penso que os mesmos passos estão a ser dados em diferentes contextos europeus, especialmente pelos coletivos negros. Há esforços muito concretos no sentido de problematizar essa questão e de tornar o problema visível, e também de propor alternativas, destacando-se aqui a questão da História. No contexto britânico, por exemplo, tem a iniciativa History Matters, fundada por Hakim Adi, intelectual acadêmico do pan-africanismo, que tem feito uma série de atividades com professores de História que são negros e se juntaram para pensar maneiras diferentes de ensinarem História ${ }^{9}$. Algumas iniciativas neste

9 Hakim Adi é professor de História de África e da Diáspora Africana na Universidade de Chichester, Inglaterra. É 
sentido são dispersas e não são iniciativas sistemáticas, não têm a força de trazer uma mudança como vocês conseguiram no Brasil. Eu acho que o caso do Brasil é fulcral para nós termos um horizonte do que nós queremos conseguir e dos problemas que nós vamos encontrar no caminho, que é como conseguir uma mudança no sistema educativo obrigatório quando nós não temos professores formados para fazer a diferença. Nós temos que começar a pensar também na mudança em termos de produção de conhecimento nas universidades, já que a questão dos currículos que está sempre ligada com a questão da produção e validação do conhecimento. Por outro lado, como é que isso se articula com a vontade política dos governos que estão à frente dessas matérias? Porque são eles que, no fundo, formulam as diretrizes para avaliação do conhecimento escolar. Portanto, não pode haver uma mudança simples entre professores e associações da disciplina se tais mudanças não forem legitimadas pelos poderes políticos e acadêmicos. Eu creio que o Brasil é caso de estudo de fato fascinante para compreender como se pode trazer mudança mais substantiva que não é uma mudança meramente cosmética, mas também para compreender as dificuldades que há neste processo. E mais: é preciso fazer uma crítica do modelo positivista que muitas vezes ainda seguimos mentalmente, questionando o que é o progresso nesta matéria, uma vez que dávamos por garantido que nós conseguíamos certas conquistas e que a mudança ia ser sempre para melhor e para aprimorar o que já vínhamos a fazer. Vemos agora o contexto político atual brasileiro no qual temos uma regressão séria em inversão das políticas nessa matéria, igualmente como ocorre nos EUA.

autor de Pan-africanism and communism: the communist international, Africa and the diaspora, 1919-1939 (2013), Pan-African History - political figures from Africa and the diaspora from 1787 (2003), dentre outros. Para saber mais sobre The History Matters Group, ver: https://www. chi.ac.uk/humanities/public-humanities/reshapinghistorical-knowledge/history-matters. Acesso em: 09 mar. 2020.
Apesar disso, nós temos muitas

limitações também. Daqui a alguns

poucos anos a Lei no 10.630/2003 vai

completar vinte anos e, efetivamente, não podemos dizer que foi

implementada. Temos muitos entraves, mas que, como você mesma disse, é uma luta constante e não é de agora, vem de décadas.

ARAÚJO: E que não vai acabar agora.

\section{Exatamente! E enquanto Portugal}

apresenta, em discurso oficial, como um Estado intercultural, convidativo e acolhedor às imigrações, há um outro lado: a legislação imigratória que dificulta a regularização de imigrantes ou de filhos de imigrantes nascidos em solo português ou mesmo a própria definição de políticas como a dos bairros sociais $^{10}$, que "guetizam" especialmente imigrantes pobres, africanos e ciganos. Como você reflete as contradições e as tensões étnico-raciais em Portugal atualmente?

ARAÚJO: As contradições entre o discurso político formal contra a discriminação racial e as condições de existência das populações racializadas não devem ser analisadas como paradoxo, quer dizer, como uma contradição absurda que

10 Em Portugal, a política pública habitacional deu origem ao chamado bairro social, que existe desde o início do século $\mathrm{XX}$, notadamente destinada às populações menos favorecidas. Bairros sociais são conjuntos de edifícios construídos nas periferias das grandes cidades a partir de projetos das Câmaras Municipais (prefeituras) e/ou das freguesias (espécie de subdivisão dos municípios) para substituir as moradias improvisadas construídas pelos próprios moradores. Atualmente, sobretudo na zona metropolitana de Lisboa, os bairros sociais são, em muito, ocupados por imigrantes nascidos ou não em solo português e ciganos. Para que um estrangeiro possa concorrer a uma habitação social, além de estar na faixa de renda exigida, precisa estar em situação legal no país. Mais informações sobre a política pública habitacional portuguesa estão disponíveis em: https://www.portaldahabitacao.pt/opencms/ export/sites/portal/pt/portal/100anoshabitacao/ af_IHRU_Habitacao_Social.pdf. Acesso em: 12 mar. 2020. 
nos leva à surpresa. Quando consideramos de forma aprofundada o papel da raça nas sociedades contemporâneas, podemos observar que estamos não perante uma contradição entre princípios e práticas, mas perante estruturas históricas duradouras que persistem na atualidade: o discurso político, a própria legislação e as instituições democráticas são fundamentais para a perpetuação do racismo. 0 que digo não é propriamente novo, como se pode verificar em Barnor Hesse (2004) e Alana Lentin (2004) ${ }^{11}$. Com o questionamento à sustentação científica do conceito de raça após o fim da Segunda Guerra, prova-se de certa forma que o mito sobre ciência e raça está errado. Entretanto, provar que o preconceito consiste em pressupostos errados, em mitos e invenções - a lógica positivista que pressupõe que certas crenças desaparecem se lhes for retirado o suporte científico - não nos levou muito longe, porque na verdade o racismo persistiu e vários autores demonstraram isso mesmo. Por exemplo, por meio de uma análise do discurso da elite intelectual anglo-americana, Frank Füredi (1998) mostra como passamos, do início do século $\mathrm{XX}$ até meados do século XX, de uma situação em que se proclamava a superioridade racial declaradamente para uma situação em que se passou a condenar formalmente o racismo através do discurso (e até legalmente no contexto pós-holocausto), apesar de continuarmos a tolerá-lo na prática ${ }^{12}$. Daí que o Füredi fala de uma nova etiqueta racial, quer dizer, condena-se o conceito de raça e silencia-se o racismo. Por conseguinte, a condenação formal do racismo

11 Barnor Hesse é professor associado de Estudos Afro-Americanos, Ciência Política e Sociologia na Universidade de Northwestern, EUA. É autor de Un/settled multiculturalisms: diasporas, entanglements, transruptions (2000), co-autor de Beneath the surface: racial harassment (1992), dentre diversas outras produções. Alana Lentin é professora de Análise Cultural e Social na Universidade Western Sydney, Austrália. É autora de Racism and anti-racism in Europe (2004) e Why race still matters (2020) e co-editora de Racism and sociology: racism analysis (2014).

12 Frank Füredi é professor de Sociologia da Universidade de Kent, Inglaterra. É autor de Culture of fear (1997), The silent war: imperialism and the changing perception of race (1998) e How fear works: culture of fear in the twenty-first century (2018). é simultânea à sua tolerância na prática. Parece uma contradição quando nós vamos estudar o discurso político e os esforços dos diferentes Estados nesta matéria nos últimos 70 anos, mas na verdade verificamos que é uma constante na história. Portanto, a ideia de que o racismo resulta da inobservância entre os princípios legais e a sua implementação prática não permite avançar muito no debate se não questionarmos os pressupostos que subjazem ao entendimento e formulação do problema. Na verdade, a legislação que foi sendo implementada, é sempre uma legislação que fica muito aquém do problema que está sendo combatido. Nós percebemos, por exemplo, em termos europeus, que o monitoramento e o combate ao racismo estão muitas vezes a cargo de instituições como a ECRI (Comissão Européia contra o Racismo e a Intolerância) ou a FRA (Agência dos Direitos Fundamentais) que são, no fundo, instituições criadas sem quaisquer poderes políticos para obrigar os Estados a serem responsabilizados pelo racismo. Dá-se a aparência de que os Estados-membros da União Européia estão fazendo algo contra o racismo, mas na verdade essas instituições têm visões muito minimais sobre o que é o racismo e não abordam seriamente a questão do racismo institucional - aliás, frequentemente evadem a abordagem estrutural do problema. A questão do levantamento oficial de dados étnico-raciais por meio dos censos questão sobre a qual eu não vou alongar aqui (ver ARAÚJO, 2019/2020) - é exemplar. Há mais de dez anos que as instituições européias reportam que Portugal, assim como outros estados europeus, não coleta dados que permitem aferir as desigualdades e a discriminação étnico-racial, argumentando que a falta de dados é obstáculo ao combate ao racismo. Porém, essas mesmas instituições não têm tido a capacidade de obrigar os diversos Estados a fazê-lo, porque são instituições que não foram pensadas e desenhadas com poderes na matéria, mas apenas formulam recomendações e diretrizes políticas. Desembocamos mais uma vez na questão da contradição entre o discurso e a prática, 
quando ela em si não é capaz de lidar, social e sociologicamente, com o problema: o racismo tem sido perpetuado em contextos democráticos com condições legais e institucionais de efetivar direitos nessa matéria. Esse ponto conduz à ideia do David Theo Goldberg (2002) sobre o Estado racial, que é diferente do Estado racista $^{13}$. 0 Estado racista seria a África do Sul durante o apartheid ou a Alemanha nazista, pois são países que ativamente perpetuavam o racismo, com legislação em vigor neste sentido. O Estado racial não é abertamente racista: é um Estado que até pode negar a prática do racismo, mas que, simultaneamente, não toma iniciativas para combater o racismo de forma estrutural. O Estado racial, característico de muitas sociedades democráticas contemporâneas, aparenta ter certa neutralidade e se escuda nesta "neutralidade" para aqueles que se beneficiam do poder estabelecido possam ampliar ou redefinir as estruturas do poder. Tem implícita a ideia de que é um Estado democrático, que não discrimina, que trata todos como iguais, mas que na verdade não combate explicitamente o racismo e não se engaja contra o racismo institucional. A concepção de que nossos Estados contemporâneos são frequentemente Estados raciais vai muito além da noção do racismo como um problema de preconceitos individuais, como algo "errado" que está "na mente das pessoas", que é abordagem herdeira do entendimento sobre raça e racismo veiculado nas Declarações sobre Raça da UNESCO publicadas entre 1950 e 1967.

\section{Como é fazer crítica ao eurocentrismo a partir de uma universidade européia?}

ARAÚJ0: Em primeiro lugar, eu diria que aqui a crítica ao eurocentrismo não é fácil, e não é difícil apenas na Europa. Se as estruturas e os cânones de conhecimento eurocêntricos foram

13 David Theo Goldberg é diretor do Instituto de Pesquisa em Humanidades da Universidade da Califórnia, EUA. É autor de diversas obras, incluindo: Are we all postracial yet? (2015); Sites of race (2014); The threat of race (2008); The racial state (2002); Racial subjects: writing on race in America (1997); e Racist culture: philosophy and the politics of meaning (1993). constituídos na Europa, historicamente foram universalizados. Aliás, esse é o grande ímpeto do eurocentrismo e da abordagem eurocêntrica: o de "iluminar" o mundo sobre um certo modo de produzir conhecimento e que se foi universalizando, o que se acentuou ainda mais recentemente com a internacionalização das universidades. Logo, é difícil fazer crítica ao eurocentrismo, mas não é só em Portugal. É preciso partir de uma posição de que o eurocentrismo não é um mero etnocentrismo, é mais do que isso e, como tal, os problemas que se colocam no contexto português são problemas que os colegas na Singapura, ou em Cabo Verde, ou no Brasil, ou na Suécia também estão lidando. Falo, portanto, a partir do meu contexto e como eu tenho trabalhado. Para mim, do ponto de vista das pesquisas que eu faço, da forma como eu leciono, tem sido trabalhar com intelectuais e ideias que não costumavam circular no espaço acadêmico ou que não circulavam no âmbito de certas disciplinas. É trazer ideias e autores que foram marginalizados, mas não apenas de diversificar o currículo em termos da inclusão de alguns nomes ou figuras. São autores que foram fulcrais para nós repensarmos uma série de conceitos e abordagens, como estamos fazendo hoje. Como exemplo, como podemos descartar a crítica de Aimé Césaire (1978) no seu Discurso sobre o colonialismo, importante para ilustrar a forma como o pensamento sobre o racismo foi desenvolvido a partir do Holocausto e não do colonialismo? Foi uma crítica pioneira que começa a circular abundantemente no espaço acadêmico hoje, talvez, nos últimos 10 ou 15 anos, mas que foi formulada em 1955. Da mesma maneira, como trabalhar o conceito de racismo institucional sem trazer o trabalho dos ativistas e intelectuais negros Stokely Carmichael (mais tarde conhecido como Kwame Ture) e Charles Hamilton (1992), no livro originalmente publicado em 1967, Black Power - the politics of liberation in America? ${ }^{14}$

14 Aimé Césaire (1913-2008) nasceu na Martinica. Foi poeta, escritor, dramaturgo, político e ideólogo do conceito de negritude. Discurso sobre o colonialismo é considerado um dos marcos para formulações teóricas da pós-colonialidade. Stokely Carmichael, nome original de Kwame Ture 
Foram eles que de fato trouxeram o termo com grande força para o debate e com conceitualização crítica da noção dominante de racismo como mero preconceito individual. Então, há uma série de conceitos e abordagens que temos grande vantagem em analisar a partir da desconstrução dos cânones eurocêntricos e esses autores e ideias são fulcrais para podermos avançar em um entendimento do racismo como sendo produzido política e epistemologicamente em contextos históricos específicos. Agora, obviamente, há grande resistência e há resistência ainda maior em contextos acadêmicos burocratizados e com preocupação obsessiva com a avaliação. Exemplarmente, temos os avaliadores das universidades e dos graus acadêmicos que conferem, que vêm avaliar os cursos e seminários oferecidos e temos que ter sempre a combinação perfeita entre autores que são os autores tradicionalmente consagrados no cânone acadêmico e uma minoria de Outros para garantir que haja um currículo "equilibrado". Ainda, quando temos estudantes que são na sua maioria brancos e não se sentem "confortáveis" com as críticas de intelectuais negros, podemos ser chamados a prestar contas por fazer essas inclusões nos currículos. Isso não ocorre de uma maneira tão incisiva com outros grupos sociais, ou seja, o conhecimento produzido pelas populações racializadas tem sido frequentemente sujeito a um processo de descredibilização na própria universidade que não tem paralelo com outros grupos no século XXI.

\section{Refletindo sobre o desenvolvimento de pesquisas acadêmicas, como podemos pensar metodologias de investigação na perspectiva antirracista?}

ARAÚJ0: Essa é uma questão que eu não tenho tão sistematizada, mas gostaria de elencar

(1941-1998), foi ativista na luta pelos direitos civis e líder do nacionalismo negro nos EUA. Charles Vernon Hamilton (1929) é cientista político, líder dos direitos civis nos EUA e professor emérito da Universidade de Columbia. A obra Black Power - the politics of liberation in America é pioneira na definição conceitual de racismo institucional. algumas questões que me parecem importantes. Em primeiro lugar, em termos do que eu concebo como uma perspectiva que está preocupada com o combate ao racismo e se diga antirracista em termos de metodologia do trabalho, parece-me fundamental em todas as fases do processo de investigação atuar em colaboração com aqueles que estão no campo e que experienciam, identificam, pensam e lutam contra o racismo de forma cotidiana. Considero, assim, ser importante desde logo pensar a definição do problema e realizar investigações no cruzamento entre os meus interesses acadêmicos e as preocupações dos próprios movimentos sociais. Essa afirmação nos coloca na posição de poder ser considerada "refém" das agendas das comunidades racializadas, uma acadêmica "militante" e "enviesada" no processo de investigação, e este é um processo que conhecem bem no Brasil contemporâneo. Mas se, noutras áreas do conhecimento - e tomemos como exemplo a saúde pública -, trabalharmos sobre os impactos de certas políticas na vida dos doentes, vamos querer falar com os doentes e dialogar com as associações de doentes que se formaram para construir um espaço de reflexão sobre os problemas comuns que enfrentam. De igual forma, se estamos falando de políticas públicas para combater o racismo, queremos ouvir e falar com as pessoas que são tanto vítimas do racismo como são ativistas antirracistas e que desenvolveram críticas neste âmbito. Portanto, eu considero produtivo este diálogo com as populações que são afetadas sobre o fenômeno que estudamos e, sobretudo, com aqueles entre os demais que têm tido reflexão aprofundada sobre o problema. Tais diálogos não acontecem apenas a nível nacional: quando me dediquei à investigação sobre os livros didáticos houve influência dos debates políticos e acadêmicos no Brasil no seguimento da aprovação da Lei n⿳o $10.639 / 2003$. Alguns acadêmicos dirão que as nossas agendas são descontextualizadas e que nos limitamos a importar problemas ditos "estrangeiros"; isto é, geralmente, o caso quando 
trabalhamos sobre o racismo e mencionamos o Brasil, os EUA ou o Reino Unido. Na minha perspectiva, penso que é importante identificar temáticas e processos que têm sido de tal forma invisibilizados que não são sequer construídas como um "problema" de investigação em certos contextos. Nesse sentido, pareceu-me que havia em Portugal enorme ausência de problematização da História e do seu ensino. Eu havia observado anteriormente aulas de História para analisar outros tipos de processos, durante a investigação em pós-doutoramento, mas já era evidente a abordagem eurocêntrica que havia à História, desde a comum glorificação das chamadas "descobertas" à forma como eram interpretadas as sociedades africanas contemporâneas. Era uma questão que merecia maior desenvolvimento e um segundo olhar. Sendo assim, o projeto vem dessa reflexão cruzada entre as preocupações acadêmicas e político-sociais. Isso para dizer que, para mim, é importante conhecer de perto a reflexão e a agenda das populações racializadas, não só nacional, mas internacionalmente. A concepção dos problemas que estudamos deve estar próxima dos problemas das comunidades e isso deve ser uma preocupação, desde o início, para a investigação. Uma segunda questão que eu elenco tem a ver com a minha identidade enquanto mulher pesquisadora branca. Como tal, muito da pesquisa que tenho realizado sobre racismo tem incidido sobre políticas públicas e pessoas em lugares de tomada de decisão, fundamentalmente as elites brancas, tanto elites políticas como também simbólicas (decisores políticos, historiadores, professores etc.). Metodologicamente, uma estratégia que adotamos em vários projetos foi a de focar as pesquisas nas pessoas que estão em posições de tomada de poder. É uma decisão que se encontra com a abordagem ao racismo institucional do Ture e do Hamilton (1992) que nos leva a interrogar aqueles em "posições respeitáveis de autoridade" e aparentemente movidos por "boas intenções". Em relação às pessoas racializadas, temos adotado diálogo constante com vistas à reflexão conjunta com pessoas com comprometimento político e atuação pública. Temos esse diálogo não para "embelezar" as mesas e as salas de conferências, tampouco para fazer um espetáculo cultural, mas para refletir acadêmica e politicamente sobre os problemas, resultados e impactos da investigação. Destaco ainda, em terceiro lugar, a etapa final dos trabalhos e da metodologia de disseminação do conhecimento que é produzido. Como podemos trabalhar os resultados com públicos mais amplos? Que novas agendas de pesquisa trazem essas colaborações? Aqui em Portugal, destaco o trabalho com a ativista do Teatro do Oprimido, Anabela Rodrigues, pessoa chave no Grupo de Teatro do Oprimido de Lisboa (GTO-LX) que desenvolve o projeto Laboratório AMI-AFRO ${ }^{15}$. As colaborações permitem confluência de interesses: de um lado, aprendemos como são as leituras das pessoas racializadas com consciência política que vão à escola e lidam com aquele currículo e livros didáticos eurocêntricos que analisamos; por outro, contribuímos com análises detalhadas a partir do lugar de quem tem o privilégio de fazer pesquisa como profissão, apresentando um trabalho que já está, de certa forma, sistematizado. A meu ver, tem sido uma experiência de colaboração que produz melhores frutos do que simplesmente cada um trabalhar de forma isolada: ao refletirmos conjuntamente, acadêmicos e ativistas, provocamos questiona-

150 Grupo de Teatro do Oprimido de Lisboa (GTO-LX) iniciou suas atividades em 2003. Constitui-se como associação sem fins lucrativos e tem como um dos principais objetivos defender a igualdade de direitos, a solidariedade e o combate à discriminação motivada por origem étnica ou racial. $\mathrm{A}$ metodologia utilizada é a do Teatro do Oprimido de Augusto Boal, desenvolvida no Rio de Janeiro na década de 1960. A prática teatral do grupo visa levar o espectador a refletir sobre a sua realidade e como a sua conduta é resultado da percepção que tem das relações de poder, dos processos de dominação e de exclusão social (ARAÚJO; RODRIGUES, 2018). Já o Laboratório AMI-AFRO é composto por jovens nascidos, ou não, em Portugal, mas de populações racializadas e que vivenciam situações de opressão racial e de desigualdade racial. Por meio do teatro, jovens atores e atrizes constroem diálogo com o público no sentido de buscar respostas para superar o racismo experienciado no cotidiano (ARAÚJO; RODRIGUES, 2018). Ver também Marta Araújo e Sílvia Maeso (2019). 
mentos mais aprofundados e fundamentados relacionados à identidade nacional e ao papel cotidiano de raça na sociedade portuguesa contemporânea. Nós continuamos cada um a realizar as suas próprias iniciativas, mas também temos tentado conjugar esforços, o que avalio como muito benéfico.

\section{Pensando na atuação da Associação de} Afrodescendentes (DJASS), do Teatro do Oprimido etc., como você vislumbra daqui para frente a atuação e 0 enfrentamento ao racismo protagonizado pelos movimentos negros em Portugal? ${ }^{16}$ Há perspectivas positivas ou a postura do Estado e o racismo institucional não permitem muitas esperanças?

ARAÚJO: Acredito que a partir de um caso específico de violência policial racista, designadamente, o conhecido caso de Alfragide em fevereiro de 2015, o trabalho que já era feito no âmbito dos coletivos foi ampliado e muitas articulações têm sido feitas ${ }^{17}$. Houve esforço

16 A DJASS tem como missão defender os direitos da população negra e afrodescendente em Portugal e combater o racismo em todas as suas formas e dimensões, reivindicando políticas e práticas de igualdade. É uma organização sem fins lucrativos, de âmbito nacional, constituída em Lisboa no ano de 2016. A associação tem página na rede social Facebook: https://pt-br.facebook.com/pg/associacao. djass/about/?ref=page_internal. Acesso em: 12 mar. 2020.

170 caso de racismo e violência policial citado aconteceu na Cova da Moura, um dos bairros mais negros de Lisboa e dos mais estigmatizados de Portugal, constantemente associado ao crime. Em 5 de fevereiro de 2015, houve uma ação de revista aleatória dos moradores realizada pela polícia responsável pela região e, sem algo que justificasse, um jovem negro morador do bairro foi detido por agentes da Polícia de Segurança Pública (PSP). A violência utilizada pelos agentes na ocasião da abordagem e na consequente detenção do jovem provocou um protesto por alguns dos moradores que foram, de imediato, dispersos com tiros de bala de borracha disparados pela polícia. Outros cinco jovens, alguns integrantes da Associação Cultural Moinho da Juventude localizada na Cova da Moura, foram à esquadra (posto policial) de Alfragide para obter informações sobre a detenção do jovem e tentar prevenir maus tratos praticados por policiais no bairro. No entanto, ao se dirigirem à esquadra, os cinco jovens, todos negros, foram brutalmente agredidos pelos agentes policiais. Depois de detidos e já no interior da esquadra, mais uma vez foram agredidos, ameaçados de morte. Os cinco, além das agressões físicas, sofreram toda sorte de humilhações de conotação racista (RAPOSO et al., 2019). muito grande e muito bem-sucedido da comunidade negra envolvida na militância política, entre eles da Plataforma Gueto, em generalizar os debates em torno do racismo e da violência policial nos diversos bairros da zona metropolitana de Lisboa, demonstrando ser muito óbvio que era problema comum de vários bairros ${ }^{18}$. Isso foi um processo iniciado pela própria comunidade que culminou, em dezembro de 2016, com a carta aberta às Nações Unidas, na qual 22 coletivos se uniram para denunciar tanto o racismo institucional em Portugal como a inércia do Estado em combater racismo e em sequer admitir a existência do racismo ${ }^{19}$. Avalio que foi um momento histórico de articulação do movimento negro, pois até então nem se tinha noção da sua dimensão no contexto português. Temos visto também crescente protagonismo da comunidade cigana/Roma, que denunciou e participou de muitas ações de enfrentamento ao Estado. Tanto os movimentos relacionados à comunidade negra como a cigana/Roma adquiriram maior protagonismo no debate público, o que levou a forte viragem no panorama nacional. Em 2016 e 2017, começamos a ver maior abertura nos jornais, com crônicas de intelectuais negros do país que até então eram bastante marginalizados, à exceção de um ou dois casos. Temos visto debate público cada vez mais alargado e que deu oportunidade das populações racializadas virem a lutar de maneira mais visível e concertada pela sua humanização e dignificação. Esse era um debate que, a meu ver, estava um pouco adormecido, eram problemas que não estavam tão visíveis, mas que estavam lá e a visibilidade dessas questões é simultânea à luta dos coletivos e movimentos por autonomia política. Portanto, aqui em Portugal, já não são apenas vozes ne-

18 Ver https://plataformagueto.wordpress.com/. Acesso em: 11 mai. 2020.

19 A Carta aberta de organizações afrodescendentes portuguesas ao Commitee on the Elimination of Racial Discrimination (CERD) está disponível em: https:// museudigitalafroportugues.wordpress.com/2016/12/08/ carta-aberta-de-organizacoes-afrodescendentesportuguesas-ao-cerd-2016/. Acesso em: 12 mar. 2020. A carta foi apresentada na sessão do Comitê realizada em novembro de 2016 em Genebra, Suíça. 
gras associadas aos movimentos de esquerda - claro que continua tendo ativistas negros ligados aos movimentos de esquerda -, mas estão articulando uma luta que é autônoma, que tem a sua agenda própria. Nós podemos dizer que em Portugal hoje há um movimento negro, que na verdade são movimentos negros múltiplos, diversos, que congregam diferentes agendas, mas que estão articulados e o momento que estamos vivenciando vai reverter ganhos e debates, com certeza. Houve ganho de articulação desses coletivos que, no contexto como é o português, uma carta aberta [enviada ao CERD, conforme última nota de rodapé] congregar 22 coletivos é um número gigante. Para o Brasil ou noutros contextos maiores pode não parecer algo significativo, mas no contexto português, que tem uma população de apenas 10 milhões de pessoas e até há pouco só se conheciam publicamente o nome de cinco ou seis coletivos, é um passo enorme, e foi dado pelos movimentos que se organizaram para combater o racismo e que conseguiram se articular em uma agenda tão bem concertada, a qual contempla desde a mudança do ensino da História à violência policial, da questão dos despejos na habitação à lei da nacionalidade ${ }^{20}$. Pode ser que vejamos tempos menos positivos, pois Portugal parece estar em contra-ciclo em relação a maior parte da Europa e de outros contextos internacionais, nos quais tem sido notório o recrudescimento da extrema-direita, o que influencia nosso cenário político também, obviamente. Contudo, por outro lado, tenho pensado positivamente, porque acho que assistimos à consolidação e alargamento da luta antirracista em Portugal e, neste sentido, sim, acho que podemos ter algum otimismo.

20 Para melhor compreensão sobre a relação entre racismo e os despejos em Portugal, ver Ana Rita Alves (2018). Diferente da legislação brasileira, para ter nacionalidade originária, Portugal não adota o princípio jus soli, em que a nacionalidade é atribuída em razão do local de nascimento. 0 Estado português adota o jus sanguinis, em que a nacionalidade e a cidadania são reconhecidas de acordo com a ascendência. Dito de outro modo, filho de imigrante nascido em Portugal é classificado como imigrante nascido em solo português. Vide Lei no ${ }^{-37}$, de 03 de outubro de 1981, conhecida como Lei da Nacionalidade.

\section{REFERÊNCIAS}

ALBERTI; Verena; PEREIRA, Amílcar A. (org). Histórias do movimento negro no Brasil: depoimentos ao CPDOC, Rio de Janeiro: Pallas, CPDOC-FGV, 2007.

ALMEIDA, Miguel Vale de. Um mar da cor da terra: raça cultura e política de identidade. Oeiras: Celta Editora, 2000.

ALVES, Ana Rita. Realojar, despejar, guetizar. Arqueologias de uma violência obliterada: habitação e racismo nos relatórios nacionais/internacionais. Relatório de pesquisa - projeto COMBAT, 2018. Disponível em: https://estudogeral.uc.pt/ handle/10316/48119. Acesso em: 12 mar. 2020.

ARAÚJO, Marta. 'Modernising the comprehensive principle': selection, setting and the institutionalisation of failure. British Journal of Sociology of Education, v. 28, n. 2, p. 241-257, 2007. Disponível em: https://estudogeral.sib.uc.pt/ handle/10316/42627. Acesso em: 14 mai. 2020.

A Fresh Start for a 'failing school'? A qualitative study. British Journal of Sociology of Education, v. 35, n. 4, p. 599-617, 2009. Disponível em: https://onlinelibrary.wiley.com/ doi/epdf/10.1080/01411920802642439. Acesso em: 14 mai. 2020.

Censos 2021 - "Raça” enterrada vida. Revista Manifesto: temas sociais e políticos, n. 4, série 2, p. 71-75, 2019/2020. Disponível em: https://ces. uc.pt/pt/ces/pessoas/investigadoras-es/martaaraujo/publicacoes/outras-publicacoes. Acesso em: 14 mai. 2020.

ARAÚJO, Marta; MAESO, Silvia R. Eurocentrism, racism and knowledge: debates on history and power in Europe and the Americas. Basingtoke/ New York: Palgrave Macmillan, 2015.

. Os contornos do eurocentrismo: raça, história e textos políticos. Coimbra: Edições Almedina, 2016. (Série Identidades e Interculturalidades - 6).

. 0 poder do racismo na academia: produção de conhecimento e disputas políticas. In: SANTOS, Boaventura de S.; MARTINS, Bruno $S$. (org.). 0 pluriverso dos Direitos Humanos: a diversidade das lutas pela dignidade. Coimbra: Almedina, 2019. p. 457-481.

ARAÚJO, Marta; RODRIGUES, Anabela. História e memória em movimento: escravatura, educação e (anti)racismo em Portugal. Revista História Hoje, v. 17, n. 14, p. 107-132, 2018. Disponível em: 
https://rhhj.anpuh.org/RHHJ/article/view/468. Acesso em: 12 mar. 2020.

BRASIL. Lei no 10.639, de 09 de janeiro de 2003. Estabelece as diretrizes e bases da educação nacional, para incluir no currículo oficial da Rede de Ensino a obrigatoriedade da temática História e Cultura Afro-Brasileira. Brasília, DF: Presidência da República, [2003]. Disponível em: http://www. planalto.gov.br/ccivil_03/LEIS/2003/L10.639.htm. Acesso em: 12 mar. 2020.

CARMICHAEL, Stokely; HAMILTON, Charles V. Black power: the politics of liberation in America. New York: Vintage Books, 1992 [1. ed. 1967].

CASTELO, Cláudia. 0 modo português de estar no mundo. O lusotropicalismo e a ideologia colonial portuguesa (1933-1961). Porto: Edições Afrontamentos (Biblioteca das Ciências do Homem), 1998.

CÉSAIRE, Aimé. Discurso sobre o colonialismo. 1. ed. Lisboa: Livraria Sá da Costa Editora, 1978.

EUROPEAN COMMISSION AGAINST RACISM AND INTOLERANCE (ECRI). Relatório da ECRI sobre Portugal (quinto ciclo de controlo), 2018. Disponível em: https://rm.coe.int/fifth-report-onportugal-portuguese-translation-/16808de7db. Acesso em: 10 mar. 2020.

FREYRE, Gilberto. Casa-grande \& Senzala: formação da família brasileira sob o regime da economia patriarcal. 34. ed. Rio de Janeiro: Record, 1998.

Aventura e rotina: sugestões de uma viagem à procura das constantes portuguesas de carácter e acção. 2. ed. Lisboa: Edição Livros do Brasil, 1952. (Colecção Livros do Brasil).

FÜREDI, Frank. The silent war: imperialism and the changing perception of race. Londres: Pluto Press, 1998.

GILLBORN, David. Racism and antiracism in real schools: theory, policy, practice. Buckingham: Open University Press, 1995.

GOLDBERG, David. The racial state. Malden, MA: Blackwell Publishers, 2002.

GOMES, Nilma L. 0 movimento negro educador: saberes construídos nas lutas por emancipação. Petrópolis: Vozes, 2017.

HESSE, Barnor. Im/plausible deniability: racism's conceptual double bind. Social Identities, v. 10, n. 1, p. 9-29, 2004. Disponível em: https://www. tandfonline.com/doi/full/10.1080/1350463042 000190976 . Acesso em: 14 mai. 2020.

LENTIN, Alana. Racism and anti-racism in Europe. Londres: Pluto Press, 2004.

MENESES, Maria Paula G. O 'indígena' africano e o colono 'europeu': a construção da diferença por processos legais. e-cadernos CES [Online], n. 7, 2010. Disponível em: http://journals.openedition. org/eces/403. Acesso em: 9 mar. 2020.

PEREIRA, Amílcar A. 0 movimento negro brasileiro e a Lei no 10.639/2003: da criação aos desafios para a implementação. Revista Contemporânea de Educação, v. 11, n. 22, p. 13-30, ago./dez. 2016. Disponível em: https://revistas.ufrj.br/index.php/ rce/article/view/3452. Acesso em: 8 mar. 2020.

PORTUGAL. Lei da Nacionalidade. Lei no 37, de 03 de outubro de 1981. Disponível em:https://dre.pt/web/guest/legislacaoconsolidada/-/lc/69738105/201708271644/ exportPdf/normal / 1 / cacheLevelPage? LegislacaoConsolidada_WAR_drefrontofficeportlet rp=diploma. Acesso em: 7 mai. 2020.

Despacho normativo no 63, de 13 de março de 1991. Ministério da Educação. Cria o Secretariado Coordenador dos Programas de Educação Multicultural. Disponível em: https:// dre.pt/application/conteudo/475368. Acesso em: 9 mar. 2020.

RAPOSO, Otávio et al. Negro drama. Racismo, segregação e violência policial nas periferias de Lisboa. Revista Crítica de Ciências Sociais, n. 119, p. 5-28, set. 2019. Disponível em: http:// journals.openedition.org/rccs/8937. Acesso em: 8 mar. 2020.

VALA, Jorge; BRITO, Rodrigo; LOPES, Diniz. Expressões dos racismos em Portugal. 2. ed. on line, Lisboa: ICS, 2015. (Estudos e Investigações, volume 11). Disponível em: https://estudogeral. sib.uc.pt/handle/10316/18440?mode=full. Acesso em: 14 mai. 2020.

VALENTIM, Joaquim P. Escola, igualdade e diferença. 1. ed. Porto: Campo das Letras, 1997. Disponível em: https://estudogeral.sib.uc.pt/ handle/10316/18440?mode=full. Acesso em: 9 mar. 2020.

Recebido em: 16/05/2020

Aprovado em: 20/06/2021 